\title{
A "FAMÍLIA POLICIAL": VINCULAÇÕES E IMPLICAÇÕES ENTRE RELATO E INSTITUIÇÃO
}

Mariana Sirimarco

Era o meu primeiro dia de trabalho de campo na Escuela de Suboficiales y Agentes da Polícia Federal Argentina (PFA) e procurava pelo Chefe do Grupo de Estudos, o subcomissário B., com quem eu deveria falar. Em seu escritório me disseram que ele estava aplicando prova e que eu tinha de esperar. Decidi fazer isso no café. A escola estava quase vazia. As aulas terminavam alguns dias depois, e a formatura seguinte já ocorreria no novo prédio para o qual a escola se mudaria.

Entrei no café, pedi um cappuccino e sentei a uma mesa ao fundo. Havia vários Aspirantes ${ }^{1}$ dando voltas por ali; alguns com terno e gravata e bolsas grandes. Estavam ensaiando, pelo que escutei, para a entrega de diplomas. Depois de um tempo, um grupo sentou-se a uma mesa perto da minha. Olhavam para mim de soslaio e faziam comentários que eu não podia ouvir. Passado um momento, um deles se aproximou e pediu que tirasse uma foto deles:

Aspirante: Você é Agente?

Mariana: Não.

A: E o que está fazendo aqui?

M: Estou esperando uma pessoa.

A: Alguém em quem você está aplicando prova final?

M: Não. Estou esperando o Subcomissário B.

A: Você é filha dele?

M: Não.

A: A sobrinha, então...

M: Também não. Não sou nada dele.

A: Então deve ser da Investigação... 
Assegurei a ele que não. Em seguida, outro Aspirante se aproximou e me perguntou:

A: Você é mesmo a sobrinha de B.?

M: Não.

A: Mas ele disse - e aponta para o Aspirante anterior.

M: Mas não é verdade.

A: Amiga, então?

M: Também não. Não sou nada dele.

O que nesse primeiro momento me pareceu estranho - entrar em um ambiente policial e ser rotulada como "Agente, filha, sobrinha ou 'amiga'" tornou-se, com o passar do tempo e os sucessivos trabalhos de campo, moeda corrente. Entendi que a minha presença parecia poder se resolver facilmente por meio do recurso ao próprio âmbito: uma mulher jovem e sem uniforme se transformava, numa escola de polícia, em alguém que pertencia ou queria pertencer à instituição policial (Sirimarco 2009, 2010; Daich \& Sirimarco 2009). ${ }^{2}$ De certa forma, me acostumei. Eu estava sempre esclarecendo as pessoas durante o trabalho de campo que eu não era da Investigação nem tampouco filha do diretor. Aos novos conhecidos, que meu pai não era policial. Em um e outro caso, a frequência a certos espaços e o interesse por certas temáticas pareciam garantir, quase de antemão, a existência de laços profissionais ou de parentesco com a "família policial". ${ }^{3}$

Esta categoria enraíza-se fortemente na instituição policial. Alude, em primeira instância, às redes de parentesco e afinidade de cada policial: seus pais, cônjuges, filhos, irmãos. Já que é muito corriqueiro encontrar policiais cujos pais ou irmãos também o são, as redes parecem urdir um grupo mais ou menos fechado sobre si mesmo. Isto se torna a tal ponto importante que a existência de consanguíneos dentro da instituição era, pelo menos há alguns anos atrás, uma pergunta obrigatória nos formulários de ingresso às escolas (tanto quanto a inexistência de parentes policiais era uma forma que muitos escolhiam para prestigiar seu ingresso):

\section{EXISTÊNCIA DE UM POLICIAL NO SEGUINTE VÍNCULO}

Pai, mãe, avô/ó, irmão/ã, tio/a, meio-irmão/ã dos candidatos, aposentados ou falecidos. Abster-se de mencionar outro parentesco. ${ }^{4}$

O que essa particularidade criava era um universo em que - para aqueles que tinham familiares policiais - o fracasso no ingresso na instituição parecia ser quase impossível, e a trama não fazia senão se estreitar: 
M: Mas [o ingresso] não é tão exigente que um monte de gente fica de fora desse processo?

Cadete: ${ }^{5}$ Não, é uma simulação. Na verdade, já sabiam quem ia entrar e quem não iria.

M: E como sabem isso? Por quem te recomenda?

C: Sim, é o que mais vale. Eu fui considerada apta no psicológico, apta em tudo, e não recebi "apto" no exame médico porque perderam as análises. Então comentei com o marido de uma amiga minha, cujo irmão é comissário. Porque ali você não vale como pessoa, vale pela hierarquia que você tem. Então, eu fui falar com ele. "Esta moça está com tudo apto, mas perderam as análises dela e, por causa disso, ela vai ficar de fora...". Depois de 15 dias, entrei. Depois, passado um tempo, tinha um oficial com um cargo muito alto lá na Escola que me disse: "Sabe, C., por que não entrou? Porque você estava em terceiro na média geral, então incomodava a filha de alguém". Para que pudesse entrar outra, colocaram que eu não estava apta, você fica de fora... O rapaz que entrou comigo naquele ano já sabia que entraria. Ainda por cima na [Escola] de oficiais. Na de suboficiais é diferente, mas na de oficiais é onde se chega a comissário, aos cargos mais altos. Todos os filhos de passam por ali.

Mas a categoria "família policial" opera também em outro sentido, desvinculando-se daquele mais literal, ${ }^{6}$ familiar, e deslizando para concepções mais próximas do metafórico. Nesta última acepção, a "família policial" já não dá conta da relação que se estabelece no interior dos grupos conformados por membros policiais, mas passa a vincular todos estes grupos entre si.

O recurso a tal discurso é de longa data. Em 1939, um integrante do que em seguida se tornaria a PFA despedia-se do seguinte modo de um companheiro nas páginas de uma revista da instituição:

Tomás Ramón Soto é o nome de outro membro da família policial que paga com a sua vida a defesa da Sociedade, obrigação inevitável de todo aquele que faz parte da Instituição mantenedora da ordem pública [...] Os irmãos policiais de Soto saberão levar a seu termo a investigação, para encontrar essas mãos que impunemente executaram o crime e para preparar a consequente condenação que, em seu devido tempo, chegará. A família policial é grande por si, mas se engrandece diante dos contrastes que sua inevitável missão de mantenedora da ordem pública acarreta (Perrone 1939).

A "família policial" não remete aqui aos laços de um indivíduo — Tomás Ramón Soto, por exemplo - com seus parentes, mas vincula uma pessoa a um coletivo maior. A família do sargento Soto não está configurada, neste 
caso, por seus pais ou prováveis filhos. Está configurada por seus companheiros: por aqueles irmãos policiais que levarão a cabo a investigação, encontrarão as mãos que executaram o crime e prepararão a condenação que chegará. A família que se nomeia aqui é a que compartilha um destino comum - a inevitável missão de manter a ordem pública — e, ao fazê-lo, define posições: aqueles que pertencem a ela e aqueles que lhe são alheios. A "família policial", afastada de seu sentido "literal" de parentesco, concebe uma maneira contundente de se referir à instituição inteira.

Este trabalho procura se ancorar justamente nestes usos e sentidos da "família policial": naqueles que remetem a um modelo discursivo apto a configurar uma determinada história institucional, isto é, aqueles que, na tentativa de construir uma identidade coletiva, apelam para narrativas de continuidade, de relacionamento, de pertencimento e de união que se tingem profundamente de categorias, sentidos e imagens provenientes do mundo familiar. ${ }^{7}$ Por que a agência policial escolhe, em determinados momentos e situações, se narrar como "família"? ${ }^{8}$ Que lógicas, sentidos e identidades podem ser construídos por meio das relações de parentesco? Por que o discurso familiar se torna um campo fértil para modelar grupos sociais?

Bestard (1998) aponta que perguntar-se pelos feitos do parentesco significa perguntar-se pelo processo específico mediante o qual o indivíduo se torna uma pessoa social e, além disso, pelas concepções sociais através das quais se constituem as relações entre elas. Tendo isto em mente é que surgem estas questões, como modo de reconhecer a importância — o sentido, as implicações - que reveste o relato, pode-se dizer analógico, a partir do qual se constrói uma determinada instituição.

O parentesco foi um dos tópicos fundadores da antropologia como ciência. Considerado a principal instituição das sociedades primitivas - aquela capaz de ordenar as demais e torná-las explicativas - o etnógrafo se especializou, entre outras coisas, em procurar, identificar, descrever e classificar, em cada sociedade-outra, o sistema de parentesco. A tal ponto foi assim, que seu estudo e seu conhecimento muito cedo se fundiram com o conhecimento etnográfico per se, legitimando a antropologia como ciência, isto é, dotando-a não somente de uma especificidade temática, mas também de um conjunto de tecnicismos, formalismos e linguagens específicas - clãs, linhagens, sociedades matrilineares, primos cruzados - que a construíam e delimitavam como campo autônomo de saber (Bestard 1998). 
O parentesco cresceu, assim, não apenas como campo de estudo, mas como relato omni-explicativo: inquestionável em seu estatuto de realidade social existente, tornou-se a instituição cardeal das sociedades primitivas, sendo entendido (construído) como a instituição que cruzava toda a estrutura do grupo e mantinha de pé o sistema político da tribo. O parentesco se transformou, no estudo dessas sociedades, não apenas na instituição por antonomásia, mas no idioma social por excelência (Bestard 1998).

É neste sentido, do parentesco como relato, que quero me deter: neste sentido de ficção modelar que narra e constrói, mediante esta narração, uma determinada forma de se relacionar socialmente. O parentesco, é sabido, se fabrica, ou seja, se constrói com base em diferentes elementos - na nossa sociedade, tanto biológicos como sociais - que permitem a construção e a manutenção de bens (terras, títulos, poderes, status) e relações sociais.

A pergunta que guia este trabalho busca elucidar o que acontece quando este relato, que se constrói como "verdadeiro" nos domínios sob o seu alcance, é aplicado a outros contextos em que seu caráter de construção figurada se torna mais evidente. Como se fabrica o parentesco qua estrutura e como se extrapolam, de um âmbito a outro, os elementos e significados capazes de narrar-nos como parentes e família? Ou, dito de outra forma, o que nos diz o idioma do parentesco em relação à "família policial"?

É preciso fazer uma ressalva. Parentesco e família têm sido largamente conceituados como categorias diferenciadas, assinalando-se esta última como aquele grupo mais delimitado do parentesco que não apenas une pessoas que compartilham uma descendência genealógica, mas também aquelas ligadas por relações de casamento. A família é resultado, então, daquele conjunto que tem origem na aliança de indivíduos que se unem por laços, direitos, obrigações e prescrições de tipo distinto (Lévi-Strauss 1996; Bourdieu 1994; Bohannan 1996). Parentesco e família são, neste sentido, categorias que aludem a significados não necessariamente redutíveis a uma mesma dimensão de análise. As duas categorias se encontram, contudo, fortemente imbricadas em nossas sociedades devido ao nosso modelo de parentesco cognático e ao papel central que nele ocupa a estrutura de família. É por isso que considero que, para efeito deste trabalho, a análise relativa ao sistema de terminologia, atitudes e sentidos implicado na noção de "família policial" pode ser subsumida e sustentada, em termos gerais, a partir da teorização relativa à fabricação de parentesco. ${ }^{9}$

Ao menos no que diz respeito à tradição ocidental, o componente biológico foi um dos elementos principais desta fabricação. Em que pesem os avanços técnicos, legais e sociais que se vêm realizando no contexto do ordenamento familiar que contribuíram para erodir a conjunção de sentido 
entre parentesco e consanguinidade, os laços de sangue continuam sendo um dos insumos principais no universo simbólico da construção do sistema de parentesco.

A "família policial" não escapa a esta afirmação. Há alguns anos, falando com um oficial da PPBA a respeito do estado policial que os agentes em serviço adquirem pelo desempenho de sua função - e que o distinguiria da sociedade civil — ele comentava: "Já vem de cima. Desde a escola nos dizem "vocês têm sangue azul", até discriminando os suboficiais. Já a partir daí nos falam do estado policial, que não somos mais civis".

O "sangue azul" torna-se um tópico recorrente dentro da instituição policial. Utilizado intramuros, serviu sempre - como esta citação evidencia para caracterizar o quadro de oficiais (em contraposição ao de suboficiais). Em momentos de maior amplitude discursiva, o "sangue azul" identifica todos os policiais como tal (em contraposição àqueles que não pertencem a uma força policial). "Nossa cor é o azul, limpo e soberano", dizia um Chefe policial há décadas. ${ }^{10} \mathrm{E}$ assim o azul — da bandeira, da pátria, do uniforme - se torna a tal ponto um sinônimo da agência policial que referir-se aos "homens de azul" é aludir aos policiais. ${ }^{11}$

À semântica do azul soma-se a do sangue, que apenas reforça a diferenciação que a primeira esboça. Se a autoridade de vestir o azul implica uma espécie de separação em relação àqueles que não o vestem, ${ }^{12}$ sua ligação com o sangue converte a distinção em realce: não escapa a ninguém que a possessão de sangue azul é o que diferencia a realeza dos simples mortais.

Mas o apelo ao sangue opera em um nível mais profundo. A procriação e a biologia são o substrato sobre o qual se cimenta a legitimidade de nosso sistema de parentesco. O biológico - a consanguinidade, a herança genética, aquilo que se traz no sangue - não só atravessa, mas funda nosso modelo de parentesco, a tal ponto que o que é uma ferramenta narrativa como qualquer outra passa a se converter num dado concreto: a consanguinidade é parte imprescindível para o amoldamento do vínculo. O biológico entendido como um feito da ordem da natureza - aparece, então, construindo o parentesco.

Neste contexto, não surpreende que o sangue, como um dos insumos mais férteis de conotação do biológico, se fundamente no simbolismo por excelência para relatar o parentesco e a família. Desde que o sangue puxa até o que se traz no sangue, este funciona como insumo ordenador do próprio e do alheio, unificando e delimitando pertencimentos. Ancorado em sentidos biológicos e por isso pretensamente naturais, o sangue passa - em virtude desta rica simbologia - de implicar parentescos "reais" a sugerir parentescos discursivos. E o faz pondo em funcionamento, quer se trate de 
um ou de outro caso, os mesmos recursos simbólicos: o da natureza como ordem do que é a-histórico e primigênio e, em concordância, do sanguíneo como laço primário, na medida em que se refere aos fatos que estão antes e mais além da cultura.

O laço de sangue se torna, assim, primordial, coesivo, perdurável. O que se leva no sangue se leva desde antes e para sempre. O sangue não só é a raiz e a origem; enquanto metáfora de vida é, de alguma maneira, o que nos faz sermos nós mesmos. Recorrer ao sangue se torna assim um meio fecundo para que a estruturação social assuma vieses particulares. Recorrer a ele é apostar na criação e na manutenção de laços que se pretendem tão centrais como inquebrantáveis. É afirmar que quem os compartilha está unido por vínculos que os tornam coesos. É sustentar, para voltar ao caso policial, que os que possuem "sangue azul" estão atados por laços que não são contingentes e sim predestinados, que não são membros só de uma instituição, mas de uma família e que, portanto, não devem se ver como colegas e sim como irmãos: "Senhores Oficiais: quando chegastes a esta Escola trazíeis a sensação do desconhecido, fostes recebidos por colegas que cimentaram ainda mais os laços de irmandade policial". ${ }^{13}$

Esta alocução, que abre um espaço de boas-vindas institucional, nos permite alcançar uma questão maior, que soma ao relato do parentesco outro elemento constitutivo: aquele que se volve a um sistema de apropriação do indivíduo. Muitos autores chamaram a atenção para o caráter social do engendramento, como inscrito em um sistema de parentesco que o precede e do qual extrai seu significado. Todo indivíduo está, assim, engendrado no marco de um grupo que determinará vínculos, favorecerá comportamentos e estabelecerá responsabilidades. É dentro do sistema de parentesco que o indivíduo aparece primeiramente situado, onde se prepara e começa a apropriação do indivíduo pela sociedade (Godelier 1993; Bestard \& Marre 2004; Théry 2009).

O engendramento transcende o dado biológico do nascimento: implica a entrada em um mundo determinado de significação e interlocução; implica, por isso, a transformação de um indivíduo em pessoa social. Sentidos similares, acredito, cabem na narração do ingresso à instituição policial. Tal como sugere a citação anterior, a escola marca o espaço das boas-vindas: da entrada em um âmbito no qual os futuros policiais são recebidos por colegas que são na realidade irmãos. Levando em conta que os espaços de ingresso à instituição podem se revestir como âmbitos de separação (entre a vida civil que se deve abandonar e a vida policial que se deve construir), ${ }^{14}$ pode-se sugerir então que a incorporação à agência policial roce sentidos de procriação social, na medida em que os indivíduos (civis) que nela ingressam são 
acolhidos em um novo sistema de legitimação e configuração social, isto é, na medida em que "nascem" na "família policial": ${ }^{15}$

Velha Escola, forjadora de gerações inteiras de policiais, fundamento de nosso prestígio institucional! Sob teu nome colocamos estes modestos esforços de quem, como filhos agradecidos, e em primeiro lugar o teu predileto, o Inspetor Geral Gamboa, o primeiro chefe que formaste, não fazemos mais do que retribuir os teus dons e tentar te engrandecer, porque assim engrandecemos a Polícia Federal Argentina! ${ }^{16}$

Que a instituição policial seja esse progenitor capaz de forjar filhos agradecidos nos leva a outra dimensão da analogia: a conhecida associação entre polícia e tutela, na qual as forças de segurança (policiais, militares) foram largamente sinalizadas — como espaços de produção de masculinidade hegemônica - como âmbitos de concentração da ordem e da respeitabilidade diante de uma sociedade muitas vezes desordenada (Bonaparte 1997; Salessi 2000; Sirimarco 2009). ${ }^{17}$ Era isto que me contava um antigo oficial da PPBA ao narrar o seu ingresso na instituição:

Entrei porque naqueles anos, fim da época militar, estava definido, nas forças
armadas e nas forças semimilitarizadas, que a pessoa tinha certo e determinado
poder. Tem a ver com o que significa um espaço de poder de que em algum
momento se precisa. O espaço de poder que depois entendi que precisava tinha
a ver com o poder da lei. A lei instaurada como ausência de mãe ou de pai.
Dentro de uma concepção ampla. Pai falecido, mãe velha. A pessoa procura
inconscientemente uma instituição rígida, algo que ocupe o lugar de mãe, pai,
ou de cuidador, ou de referente. Entendi esse espaço como um espaço valioso
que poderia suprir a ausência de pai. Eu via isso como algo que me dava uma
sensação de força, de certa proteção. Era uma coisa muito forte, tinha uma
representação importantíssima dentro da sociedade.

Sangue azul, irmandade, filiação, progenitor, tutela. Estes são alguns dos elementos, entre outros, com os quais a instituição policial se narra enquanto "família". A família - muitos autores já concordaram — pareceria não requerer explicação, ao aparecer como um atributo da condição humana: como a mais natural de todas as categorias (Bourdieu 1994; Zonabend 1986). As páginas subsequentes são uma tentativa de distender estas afirmações e desnudar a lógica de sentido que faz da família uma matriz ordenadora de outros grupos sociais. 
Perguntava-me, no início deste trabalho, por que a instituição policial escolhia se narrar enquanto "família". Colocar-se esta questão implica assumir duas posições. A primeira, que toda instituição constrói relatos que a sustentam: narrativas que põem em cena discursos, vivências e valorizações a partir das quais se pensa como grupo social e como instituição. A segunda, que assim como não existe instituição sem relato (não existe instituição que não se narre), não existe relato sem implicação política. Neste jogo de se narrar e de se reproduzir, o apelo a determinados sentidos não é ingênuo, e guarda estreita relação com os modos pelos quais se espera que instituição e relações sejam assumidas.

Esta assunção vai, pode-se dizer, muito além da mera caracterização. O objetivo não repousa tanto na pretensão de conceituação como na de vivência, já que construir um relato não é tentar reclamar uma forma de entender grupos e indivíduos, mas sim de buscar reivindicar uma modalidade de experimentá-los. A esfera central de um relato institucional não é, portanto, a da intelectualização, e sim a da vivência: se o relato institucional recorre ao uso de imagens e analogias, não é para dizer a seus membros que se pensem como "família policial", mas para dizer-lhes simplesmente que o são.

É neste contexto de entendimento que a pergunta sobre o discurso do familiar adquire sua relevância, já que evoca lógicas e sentidos passíveis de estruturar, de uma forma particular, a dinâmica institucional. A noção de "família policial" remete, assim, em primeiro lugar, à ideia de um todo que, embora seja formado por indivíduos, está, por sua vez, acima destes, de tal forma que a soma das partes conforma uma totalidade que os transcende. Bourdieu (1994) disse isso de outra forma, ao afirmar que a família foi concebida como um personagem transpessoal, dotado de uma vida e um espírito comuns. Este "espírito de família" justifica a ordem e a hierarquia de cada um, mas o faz apelando para algo que o transcende: essa vontade única que parece ser muito mais que a soma de todas as vontades.

Falar assim de "família policial"18 implica falar de uma figura de reunião: de uma totalidade que não se divide em indivíduos isolados, mas individualidades solidárias, isto é, que agrupa, ligando indissoluvelmente cada parte do sistema, de maneira que o "bem familiar" se encontra acima do bem de cada membro. ${ }^{19}$

Falar da "família policial" é, por isso também e em segundo lugar, falar de ordem. Não por acaso a família tendeu a ser caracterizada como a forma mais básica de estruturação social. Uma ordem que, por um lado, estabelece as diferenças e as hierarquias internas - entre pais e filhos, superiores e subor- 
dinados - mas que, por outro, subsume-as em uma hierarquia maior: o filho ao pai, o sargento ao comissário, o policial à instituição. O discurso de família é a idealização romântica da ordem que unifica, hierarquizando diferenças.

Consegue, ao fazê-lo, um objetivo fundamental: o de dizer e negar, em um mesmo movimento, tanto o diferente como o desigual; o de afirmar que todos temos diversas tarefas, papéis e cargos, mas que todos somos iguais em nossa necessidade de servir, com eles, ao grupo do qual somos parte. Esta disposição de igualdade diante do que nos transcende não procura desconhecer, contudo, nossa desigualdade horizontal. Nem procura escamotear tampouco a instauração, sob o manto de unidade, de uma hierarquia reconhecida e definida. Logo, se é certo que todos os membros da família são, apesar de suas diferenças, igualmente importantes, também é certo que toda estrutura familiar apresenta - discursivamente falando - um "cabeça de família".

Esta figura capital, que serve sem dúvida para a hierarquização e o ordenamento intrainstitucional, tem também, na "família policial", outro campo de aplicação, mais ligado ao seu posicionamento diante da sociedade maior. No seu tratado sobre a polícia, o comissário Leopoldo Lugones (filho) utilizava uma comparação amplamente sugestiva para defender uma instituição acusada, naquele momento, de despotismo. Dizia que:

Quando no seio de uma família numerosa um dos progenitores exerce cabalmente a autoridade paterna, põe nos trilhos o filho relutante, limita prudentemente os gastos e mantém uma ordem caseira e primordial, nunca falta o rebento que murmura contra a tirania do lar (Lugones 1943:11).

A polícia é claramente o progenitor que exerce cabalmente a autoridade paterna. Voltamos com isso, uma vez mais, à construção da polícia como pater familiae (pater enquanto autoridade, não necessária e literalmente enquanto pai). Ou, em outras palavras, voltamos à figura policial como foco de autoridade, em que sua ação não pode jamais ser confundida com uma atividade tirânica, posto que emana do exercício cabal de sua função. Se sua autoridade nunca pode se tornar autoritarismo é porque se trata de uma autoridade legitimamente exercida: porque se trata, assim como a autoridade do pai na família, de uma autoridade que traduz a assimetria de posições (pai-filho) em termos de uma superioridade moral naturalmente constituída. Uma vez construída esta imagem, o paternalismo e a tutela tornam-se anuláveis. ${ }^{20}$

Se esse recurso à família tem algum resultado, é o de apresentar este ordenamento, em terceiro lugar, em termos de naturalidade inquestionável. Dizíamos que a família se construía fortemente sobre o paradigma do biológico, adjudicando-lhe, no âmbito da natureza, tons de autenticidade pri- 
mordial, em que o laço biogenético - o dos parentes por meio do sangue se constrói como laço verdadeiro.

Assim, e enquanto a família se apresenta como categoria natural, ser membro da "família policial" é dar a conhecer esta modalidade de relacionamento, graças a esta raiz naturalista que faz da família o lugar do verdadeiro, como uma forma de vinculação genuína e inquestionável. Recorrer à "família policial" não é apenas apelar para a subsunção do indivíduo no todo, mas sim revestir esta subsunção de traços específicos de inegável naturalidade.

E é aqui que essa subsunção adquire um tom particular, pois, em quarto lugar, a família não somente foi considerada âmbito por antonomásia do íntimo e do privado, mas também, e em concordância, foi entendida como o espaço por excelência do cuidado e do (bom) sentimento. Tem sido dito amplamente que as relações de parentesco se entranham numa espécie de relacionamento ético: uma série de deveres e direitos morais que conectam as pessoas e implicam atender, gostar de e se preocupar com aquele que é nosso parente (Borneman 1997; Bestard 2004; Daich 2011). O laço familiaro laço de sangue - é o laço mais puro: não se move pelo interesse nem é contaminado pelo político, sendo regido pelo cuidado, a preocupação, o carinho e a confiança.

A família vem a ser então aquele universo de sentido que entranha uma descrição - o universo do sagrado, do secreto, do íntimo - e uma prescrição: designa, lexicalmente, aqueles considerados parentes, e prescreve um sistema de atitudes e dispõe, entre seus membros, afetos, generosidades e solidariedades (Bourdieu 1994; Zonabend 1986). Disso resulta a consagração da família como esfera de amor, cuidado, lealdade, favor e reciprocidade, na qual os intercâmbios são desinteressados, impolutos, pois se realizam voluntária e alegremente, sem calcular benefícios nem esperar recompensas, apenas por afeto e solidariedade.

O papel dos sentimentos é, assim, primordial na construção de parentesco, já que essa estrutura não pode se perpetuar a não ser recriando continuamente o sentimento familiar; ou seja, criando repetidamente a coesão não em termos de conveniência, mas de apego, e obtendo de seus membros uma adesão vital e afetiva à existência de um grupo familiar e seus interesses (Bourdieu 1994). O sentimento, diria Leavitt (1996), se torna uma performance comunicativa que não só implica formas de sentir, como instrui sobre formas de atuar.

Aludir à "família policial" é, portanto, deslocar a lógica de relacionamento do profissional para o privado, fazendo com que as relações próprias da instituição policial pareçam obrigadas por lealdades e aproximações, antes que por estruturações hierárquicas ou regulamentárias: 
O espírito de solidariedade é um sentimento e um dever que as ordens policiais vigentes estimulam a todo momento. A solidariedade moral, que deve reinar entre todos os policiais, deve se caracterizar pela fortaleza, a compreensão e a união no exercício da profissão, que distribui igualmente inquietudes e sentimentos a cada um de seus membros [...].

O policial deve fortalecer os vínculos de solidariedade que o aproximam de seus companheiros. Os laços de camaradagem excluem as pendências, as invejas, as violências. Esta camaradagem impõe o dever de se ajudar, de se estimular, sobretudo com o bom exemplo, respeitando-se uns aos outros. ${ }^{21}$

Assim, o relato familiar percorre o eixo de entendimento e propõe um modo de vivenciar o relacionamento que pouco tem a ver com aquele de uma organização institucional burocratizada. Se o apelo à "família" consegue alguma coisa, é apresentar o ordenamento social em termos de respeito e solidariedade ao remeter a uma ficção idealizada da igualdade que consegue encobrir suas arestas mais desiguais e hierárquicas. Nomear uma instituição enquanto "família" é apelar, assim, para uma identidade cristalizada que, ao se apresentar como o lugar de produção dos laços mais essenciais, produz uma imediata suspensão de qualquer tipo de diferença política ou social (Pita 2010).

Mais do que isso: se o laço de parentesco, por estar fundamentado na noção do natural como genuíno, é aquele laço de afinidade que não deveria despertar nada além de afetos e lealdades, a "família policial" recorre, em virtude desta denominação, a um modo de vinculação em que qualquer distância diante destas atitudes fica semanticamente obstruída. Qualquer atitude, por recorrer a um só exemplo, é exaltada em termos de cuidado: cuidar das costas do companheiro, cuidar da justiça e da memória do colega falecido, cuidar do ferido no cumprimento do dever, cuidar da cidadania toda. Em outras palavras, os modos de relacionamento que são próprios da instituição — obediência, hierarquias, subsunções - se apresentam, como os vínculos entre parentes, em termos do naturalmente dado e do moral e afetivamente pertinente.

\section{IV}

A família foi catalogada como o espaço do natural, como a base da sociedade, como o lugar da confiança, em suma, como o âmbito de respaldo que segue estando ali quando todas as demais instituições falham. O familiar se torna, por isto e por tudo o que foi dito, o idioma social com que se conotam 
as relações mais relevantes e a estrutura social com a qual se constroem as organizações mais verdadeiras.

Assim se entende o sentir policial, que não faz senão reafirmar a sua importância como instituição basal e organizadora do social, como vemos neste trecho de um manual de instrução:

A família constitui o pilar fundamental da sociedade. Assim como ao construir um edifício nos preocupamos para que os cimentos e a estrutura sejam sólidos, do mesmo modo devemos assegurar que nossa família, de formação eminentemente cristã, vá se desenvolvendo, crescendo, sobre uma estrutura sã e sólida que resista a embates da subversão de valores, tanto morais como espirituais.

A família... nossa família! Deve estar acima de tudo. ${ }^{22}$

Procurei até agora percorrer os elementos com que se constrói o relato da "família policial", entendendo como relato a pretensão de uma voz institucionalizada que, ao ressaltar valores ou exaltar comportamentos, tenta prover um marco de entendimento no qual o policial possa pensar a si mesmo.

Falar de uma instituição não implica, evidentemente, fazer referência a uma estrutura existente por si só. Giddens (1984) sustenta que a estrutura institucional não existe como uma entidade fora dos indivíduos que a compõem, mas sim como uma encarnação de suas práticas. O rastro institucional — destaca - não se encontra fora destes sujeitos, mas justamente neles mesmos. Trata-se, em palavras de Lewkowicz (2008), não tanto de um laço, mas do modo pelo qual os indivíduos que conformam um grupo são instituídos por e para esse laço.

Falar então de um relato institucional como o da "família policial" é falar de uma narrativa que se pode dizer dominante (ainda que não necessariamente acatada), cunhada por aquelas pessoas ou por setores que conseguiram pôr em circulação, com maior êxito, um certo modo de compreensão da realidade. Trata-se de uma metáfora de construção da ordem política. A "família policial" não deixa de ser, por isso, um dos modos de se reificar a noção de instituição, na medida em que a coloca como realidade existente e externa aos indivíduos que a compõem. Enquanto propõe um modo legítimo e unívoco de verbalizar o sentir de todos, o discurso da "família policial" desnuda, precisamente nesse movimento, o da instituição policial como coisa fundada. Assim, construir discursos de unidade e transcendência o corpo, o organismo, a família - não é mais do que desvelar e ratificar o caráter equiparável entre instituição e relato.

Com este objetivo em mente, examinei nas seções anteriores aqueles materiais que entendo que condensam melhor esse registro institucional: 
revistas, livros, manuais, discursos, conferências. ${ }^{23}$ Trata-se, como ficou claro, de materiais que foram elaborados com vistas a serem enunciados em contextos de construção institucional - ciclos letivos, funerais, reuniões de camaradagem - e a exercer, portanto, certo tipo de ensino ou instrução: visando marcar posicionamentos, fixar vozes autorizadas, construir nós de sentido que unam e delimitem pertencimentos, tanto para fora como para dentro. A consulta a esses materiais não deve ser mal interpretada. Ao recorrer a eles, não pretendo afirmar que a investigação desse corpus proporcione pistas para entender práticas e sentimentos efetivos, mas sugerir que é possível vislumbrar, sob o peso enganosamente plúmbeo do dever ser, certa pretensão de caracterização da realidade simbólica e social.

O meu interesse pelo relato institucional — o da família ou qualquer outro - não implica, sob nenhum conceito, tomá-lo como realidade dada ou acreditar que seja necessariamente concordante com a voz do policial individual. O meu interesse pela construção de um discurso é um interesse pelos elementos e pela pretensão de sua configuração, em que o central não se dirime no plano real de sua escrupulosa aceitação, mas sim no plano simbólico ao qual este alude. O meu interesse por relatos e discursos policiais é um interesse, em suma, por um dos movimentos com que se cria e se sustenta a institucionalidade.

O relato institucional não o seria se não fosse possível incorporá-lo. Em 2002, o Ministério de Segurança da Província de Buenos Aires publicou um volume intitulado Con honor y dolor. Testimonios de vida de policías de la Provincia de Buenos Aires. Ele pretendia ser uma homenagem a todos os funcionários policiais incapacitados como consequência de ferimentos ocorridos em serviço. O volume, que reúne 15 testemunhos, abunda em detalhes dos enfrentamentos ou dos procedimentos que derivaram das lesões sofridas. Nele, um agente explica o quanto significou, durante sua recuperação, a dedicação de seus companheiros, tornando próprias a noção de "família policial" e sua concomitante dimensão de cuidado:

Quando voltei à minha casa vinham muitos companheiros do Comando e também do comissariado de Tigre, onde eu tinha estado antes, isso me ajudava e estar com a minha família também. Mas não queria que viesse ninguém que não fosse do "trampo" [palo], como se diz. Não queria que me vissem nem sair à rua.

Todos vinham até a minha casa e me viam não como um herói, me viam como companheiro numa situação fodida, como um amigo... Aí me dei conta de que realmente a Polícia é uma grande família. Também ajudavam muito minha mulher, ela precisava falar com alguém e ter a tranquilidade de que eu 
não tinha estado só. $\mathrm{O}$ alento é fundamental quando alguém passa por uma situação como essa (AA.VV. 2002:28).

Agora, estes relatos institucionais não conformam - como sugeri estruturas semânticas fechadas, capazes de orientar os entendimentos dos membros em sentidos sempre iguais e sempre regulados. Um relato não é uma peça unívoca, ainda que sua pretensão o seja. Trata-se, melhor dizendo, de um texto social que, apesar de compactar sentidos, evitar certas circunstâncias e ressaltar certos elementos, não consegue camuflar, contudo, o emaranhado de vozes e tradições que o compõem. Tenta-se que um relato institucional seja um discurso compartilhado; trata-se, no entanto, de um espaço em disputa.

Que isto seja assim obedece a um simples fato. Um relato pode se apresentar como uma estrutura com pretensões de se fixar como um fato semântico. Não obstante, a intencionalidade dessa vontade não condiciona necessariamente a sua leitura. A compreensão de um relato - suas aceitação, assimilação, reprodução - depende, em última instância, de leituras concretas e individuais. São as pessoas dentro e fora da instituição que, com suas interpretações, associações, sensibilidades e vivências, "leem", de forma específica, um discurso determinado. Essas leituras, sejam afins ou antagônicas, acrescentam camadas ao relato. Este se constrói numa relação de diálogo: um relato institucional o é por interpelar sentidos capazes de serem sensíveis aos atores envolvidos.

Que o relato institucional pretenda se erigir como voz monolítica não deve levar a conceituá-lo, entretanto, de maneira claustrofóbica, como se fosse uma mera instância de constrangimento social. Sua pretensão de narrativa total não impede que ele funcione como uma instância de interlocução com a qual concordar, com a qual discutir, ou contra a qual se rebelar (Loriga 1992).

O relato institucional não o seria se não fosse possível rejeitá-lo. Durante o meu trabalho de campo na Escola Superior da PPBA, uma professora comissária tentava aconselhar os alunos — oficiais com uma média de sete anos de função - em relação a algumas arestas e armadilhas institucionais:

Cuidem-se. A maior quantidade de baixas não são por feridas de bala, mas por relatórios. As estatísticas são dos comissários, não de vocês. Quem vai em cana são vocês, não os chefes. Sempre um vigilante, um oficial ajudante ou um oficial subinspetor, às vezes um oficial principal. Isso de "somos uma equipe", como diz o comissário, acaba quando não convém mais ao comissário. O que tanto falam da "família policial", se nunca me chamaram para repartir o dinheiro? 
Pode-se dizer que a voz desta comissária intervém ativamente no relato da "família policial". Mas não o faz para reafirmá-lo, e sim para resistir a ele. Sua voz dialoga com os elementos deste discurso não apenas para rejeitar a própria nomeação da polícia como família, mas, muito mais importante, para rebater seus significados e associações. Sua locução não sinaliza uma mera divergência de opiniões, mas denuncia a tentativa de imposição de um embuste - o que tanto falam da "família policial"?

O embuste radica, segundo a comissária, em sugerir que a "família policial" é uma unidade incólume, quando se trata de um agrupamento contingente, que as relações que se pretendem leais e solidárias são na realidade convenientes e assimétricas, e que os interesses espúrios e os intercâmbios desiguais - e não os sentimentos puros e as reciprocidades são de fato o pão de cada dia. Sua tentativa de impugnação da analogia familiar é na realidade a tentativa de recolocar, no entendimento do funcionamento da agência policial, aqueles outros sentidos - profissionais, institucionais, corporativos - que o tom "sentimental" do discurso familiar conseguira subtrair do olhar - o que abre para nós uma nova questão. Ou, se for preferível, uma nova dimensão da questão inicial.

Perguntei-me, no começo deste trabalho, pelos sentidos e pelas vinculações que tornariam possível que o discurso do familiar fosse proveitoso para narrar outras instituições sociais. Pergunto-me agora, já percorrido esse caminho, pelas possibilidades de que certas estruturas - e a policial entre elas - possam ser pensáveis fora do recurso ao discurso de família. A pergunta que abria este trabalho - por que a agência policial escolhe se narrar enquanto "família"? — toma então outro viés: até que ponto a recorrência ao relato de família não estanca o entendimento da estrutura policial como fechada, hierárquica, desigual? Ou, em outras palavras, que outras maneiras de construir a institucionalidade ficam abertas ao se prescindir de relatos que tanto camuflam como realçam estas características?

Recebido em 02 de janeiro de 2013

Aprovado em 11 de setembro de 2013

Tradução de Fernanda Guimarães

Mariana Sirimarco é pesquisadora adjunta do Conicet e professora da Universidade de Buenos Aires. E-mail: <maikenas@yahoo.com.ar> 


\section{Notas}

${ }^{1}$ Esta é a denominação que recebem os alunos do Curso Preparatório para Agentes da PFA. Cabe mencionar que este artigo se baseia em minha pesquisa em escolas policiais no âmbito da cidade e da província de Buenos Aires. Os trechos de entrevistas correspondem ao meu trabalho de campo no Curso Preparatório para Agentes da Escola de Suboficiais e Agentes (PFA, 1998-1999), na Escola Vucetich (1993-1995, 2003-2004) e na Escola Superior de Polícia (Polícia da Província de Buenos Aires, PPBA, 2003-2004). Trata-se, nos dois primeiros casos, dos cursos iniciais da carreira policial - do pessoal subalterno, no caso da PFA, e do quadro de oficiais, na PPBA. O terceiro caso corresponde à instituição encarregada de comandar os cursos de capacitação que o quadro de oficiais deve cumprir como condição prévia e obrigatória para a ascensão a certos graus da hierarquia. As afirmações aqui transcritas correspondem à dinâmica da instrução fornecida nos anos detalhados em cada caso. Para uma maior contextualização de tais âmbitos educativos, ver Sirimarco (2009).

${ }^{2}$ Para uma reflexão mais profunda sobre as dinâmicas e as particularidades do trabalho de campo em espaços policiais, ver Daich e Sirimarco (2009) e Sirimarco (2012).

${ }^{3} \mathrm{Ou}$ parecia garantir - coisa que continua sendo interessante para os termos deste trabalho - a subsunção de certos relacionamentos nas categorias de parentesco. É difícil não lembrar, neste ponto, como a figura da "sobrinha" serviu para velar, sob o manto de uma relação familiar que se torna por isso "inquestionável", a existência de outros vínculos.

${ }^{4}$ Escola de Polícia Juan Vucetich (PPBA). Solicitação de ingresso correspondente ao ciclo letivo de 2003.

${ }^{5}$ Esta é a denominação que os alunos recebem durante a instrução na Escola Vucetich da Polícia da Província de Buenos Aires (PPBA).

${ }^{6}$ Não procuro afirmar que a família seja de fato uma realidade biológica alheia à construção social, mas aludir, com o termo "literal", sua pretensão de sê-lo.

${ }^{7}$ Não é, portanto, objetivo deste trabalho deter-se nos modos de relacionamento familiar do agente policial. Para uma análise destas questões, ver Calandrón (2011) e Suarez de Garay (2009), entre outros.

${ }^{8}$ A instituição policial não se encontra só neste esforço. Outros grupos - nos quais a máfia constitui a famiglia por antonomásia - abundaram também neste relato estruturador, que superpõe complexamente parentescos "reais" e analógicos. Para uma análise das relações de aliança, amizade e/ou parentesco no interior do poder judicial, ver Sarrabayrouse e Villalta (2005). 
${ }^{9}$ A argumentação em torno dos matizes diferenciais entre família/parentesco é complexa e implica definições e posicionamentos não consensuais. Dar conta dela de forma cabal exigiria um nível de análise que excederia o foco deste trabalho. Para um aprofundamento neste sentido, ver Zonabend (1986), Godelier (1993), Bourdieu (1994), Lévi-Strauss (1996), Bohannan (1996), Bestard (1998).

${ }^{10}$ Última mensagem do comissário Alberto Villar no jantar anual da Camaradería del Personal Superior (Confraria dos Agentes Superiores), em 26/10/1974 (ver Muñoz 1984:174).

${ }^{11}$ Nesta mesma linha, é sugestivo observar que o Instituto Materno Infantil dependente da Caja de Retiros, Jubilaciones y Pensiones (Caixa de Licenças, Aposentadorias e Pensões) da PFA chamava-se, ao menos em 2003, "A Caixinha Azul".

${ }^{12}$ Sejam eles sociedade civil, militares ou gendarmes. Anos atrás, um aspirante me contava que seu instrutor os recebera, no primeiro dia do curso, dizendo que ele "tinha recebido 267 bostinhas e ia entregar à sociedade 267 agentes de Polícia. Esqueçam todos os bostinhas verdes, os bostinhas marrons, aqui são policiais, e não importa nem um caralho tudo que aprenderam até agora" (Sirimarco 2009). A alusão cromática, é claro, simbolizava o uso prévio de outros uniformes, implicando a passagem dos aspirantes pelo Exército e a Gendarmaria.

${ }^{13}$ Fragmento do discurso pronunciado pelo comissário Alberto Villar, em 1969, por ocasião da finalização de um curso voltado para policiais provinciais (Muñoz 1984).

${ }^{14}$ Sustentei que as etapas educativas iniciais da agência policial podem ser conceituadas enquanto períodos de separação entre o civil e o policial, na medida em que se requer o abandono irrecuperável da vida (civil) passada como condição imprescindível para se tornar policial. Para um aprofundamento desta argumentação, ver Sirimarco (2009).

${ }^{15}$ Uma vez que o ingresso na instituição policial implica a aquisição do estado policial (situação jurídica que resulta do conjunto de deveres e direitos estabelecidos pelas leis e regulamentos), o uso desta imagem pode então ser bastante pertinente. Para maiores detalhes a respeito das características desse estado policial, ver Sirimarco (2009).

${ }^{16}$ Conferência pronunciada pelo inspetor geral Enrique Fentanes na Escola de Polícia, em 29/12/1954 (Fentanes 1959:25-26).

${ }^{17}$ Basta considerar a Lei Ricchieri de serviço militar obrigatório, sancionada em 1901, que procurava estender o militar como modelo de nacionalidade e respeitabilidade burguesa rigorosamente heterossexual, em um período de construção da pátria, em que o militar constituía uma metáfora organizadora de todo um discurso sociopolítico argentino (Salessi 2000). Para uma análise sobre a conjunção entre militarismo, masculinidade e cidadania, consultar o estudo de Gill (1997) sobre o 
serviço militar boliviano como espaço de transformação de indígenas em cidadãos. Consultar também o artigo de Beattie (1996) sobre a Lei do Serviço Militar Obrigatório no Brasil em 1908, que procurava redefinir o recrutamento, antes percebido em termos de servilismo, humilhação, castigo e ameaça da masculinidade, como uma empresa eminentemente masculina.

${ }^{18}$ A "família policial", enquanto ficção aglutinadora, é indissociável de outra narrativa também cara à instituição policial: aquela relativa ao "corpo policial". Assim, são comuns as alusões à tropa como "a coluna vertebral da Instituição", ao suboficial como corpo que age enquanto a cabeça da oficialidade pensa ("você não pensa, você age. É para isso que serve a cabeça, e o resto obedece"), e ao policial como órgão de um corpo maior ("verão que, quando matam um policial, parece que arrancaram um braço de vocês"). O aprofundamento e a vinculação destas dimensões é parte de um trabalho atualmente em elaboração.

${ }^{19}$ Trata-se, é claro, de características não necessariamente reais do familiar, mas aquelas que foram selecionadas para construir uma imagem idealizada da família.

${ }^{20}$ Essa figura do pater familiae é devedora, obviamente, dos modos de construir e legitimar a autoridade em nossa tradição política.

${ }^{21}$ Manual Práctico para el Personal Subalterno. 1979. Buenos Aires: Editorial Policial. pp. 41-42.

${ }^{22}$ Manual Práctico para el Personal Subalterno (1979:49).

${ }^{23}$ A referência a materiais de diversos momentos históricos não deve afiançar a ideia de uma necessária continuidade no entendimento da instituição policial (nem dos relatos que a sustentam). A intenção é enfatizar - em diferentes tempos e publicações - a recorrência geral do discurso da "família policial", sem deixar de observar os possíveis matizes de sentido inerentes a cada situação particular. 


\section{Referências bibliográficas}

AA.VV.: Con honor y dolor. Testimonios de vida de policías de la Provincia de Buenos Aires. 2002. La Plata: Editorial Policial de la Provincia de Buenos Aires.

BEATtIE, Peter. 1996 "The house, the street and the barracks: reform and honorable masculine social space in Brazil, 1864-1945". The Hispanic American Historical Review, 76(3): 439-473.

BESTARD, Joan. 1998. Parentesco y modernidad. Buenos Aires: Paidós. - 2004. Tras la biología: la moralidad del parentesco y las nuevas tecnologías de reproducción. Barcelona: Universidad de Barcelona.

BORNEMAN, John. 1997. "Cuidar y ser cuidado: el desplazamiento del matrimonio, el parentesco, el género y la sexualidad". Revista Internacional de Ciencias Sociales, 154. Versión digital. Disponível em: http://www. redalyc.org/revista.oa? $\mathrm{id}=654$

BESTARD, Joan \& MARRE, Diana. 2004. "El cuerpo familiar: personas, cuerpos y semejanzas". In: - (orgs.), La adopción y el acogimiento: presente y perspectivas. Barcelona: Ediciones de la Universitat de Barcelona. pp. 293-311.

BOHANNAN, Paul. 1996. Para raros, nosotros. Introducción a la antropología cultural. Madrid: Akal.

BONAPARTE, Héctor. 1997. Unidos o dominados. Mujeres y varones frente al sistema patriarcal. Rosario: Homo Sapiens Ediciones.

BOURDIEU, Pierre. 1994. "Espíritu de familia". In: María Rosa Neufeld, Mabel Grimberg, Sofía Tiscornia \& Santiago Wallace (orgs.), Antropología social y política. Hegemonía y poder: el mundo en movimiento. Buenos Aires: Editorial Eudeba. pp. 57-64.

CALANDRÓN, Sabrina. 2011. "Sentidos del parentesco en trayectorias y prácticas del oficio policial". Monografía final, Seminario Problemáticas Contemporáneas de la Familia, Maestría en Estudios de Familia, Universidad de San Martín.

DAICH, Deborah. 2011. "La administración burocrática del cuidado. Justicia penal y 'conflictos de familia'". Debate Feminista, 22(44):33-59.

_ \& SIRIMARCO, Mariana. 2009. "Anita anota. El antropólogo en la aldea (penal y burocrática)". Cadernos de campo, 18(18):13-28.

FENTANES, Enrique. 1959. Didáctica policial. Fundamentos y planificación de su reforma. Buenos Aires: Ediciones del Consejo Técnico.

GIDDENS, Anthony. 1984. The constitution of society. Outline of the theory of structuration. Berkeley and Los Angeles: University of California Press.

GILL, Leslie. 1997. "Creating citizens, making men: the military and masculinity in Bolivia". Cultural Anthropology, 12(4):527-550.

GODELIER, Maurice. 1993. "Incesto, parentesco, poder". El Cielo por Asalto, 5:99-115.

LEAVITT, John. 1996. "Meaning and feeling in the Anthropology of emotions". American Ethnologist, 23(3):514-539. LÉVI-STRAUSS, Claude. 1996. "La familia". In: H.M. Velazco (coord.), Lecturas de antropología social y cultural. La cultura y las culturas. Madrid: Uned. pp. 295-318.

LEWKOWICZ, Ignacio. 2008. Pensar sin Estado. La subjetividad en la era de la fluidez. Buenos Aires: Paidós. 
LORIGA, Sabina. 1992. Soldatti. L'istituzione militare nel Piemonte del Settecento. Venecia: Marsilio editori.

LUGONES, Leopoldo. 1943. La policía. Buenos Aires: Ediciones Seamos Más Argentinos.

MANUAL PRÁCTICO PARA EL PERSONAL SUBALTERNO. 1979. Buenos Aires: Editorial Policial. pp. 41-42.

MUÑOZ, Jorge. 1984. Seguidme! Vida de Alberto Villar. Mar del Plata: Ediciones Informar.

PERRONE, Carlos: "Sargento Soto". 1939. Revista de Policía y Criminalística de Buenos Aires, tomo III, 16:62.

PITA, María Victoria. 2010. Formas de morir y formas de vivir. El activismo contra la violencia policial. Buenos Aires: Editores del Puerto/CELS.

SALESSI, Jorge. 2000. Médicos, maleantes y maricas. Rosario: Beatriz Viterbo editora.

SARRABAYRoUse OliveirA, María José \& VIllALTA, Carla. 2005. "De 'menores' al 'Camarón': itinerarios, continuidades y alianzas en el poder judicial". Ponencia presentada en las III Jornadas de Investigación en Antropología Social, Universidad de Buenos Aires, 3-5 agosto.

SIRIMARCO, Mariana. 2009. De civil a policía. El proceso de incorporación a la institución policial. Buenos Aires: Teseo.

2010. "Memorias policiales. Narrativas de emotividad". Antropología y Ciencias Sociales, IX:127-143.

_. 2012. "El policía y el etnógrafo (sospechado). Disputa de roles y competencias en un campo en colaboración". Etnográfica, 16(2):269-290.

SUAREZ DE GARAY, María Eugenia. 2009. Los policías. Una averiguación antropológica. Guadalajara: ITESO.

THÉRY, Irene. 2009. "El anonimato en las donaciones de engendramiento: filia- ción e identidad narrativa infantil en tiempos de descasamiento". Revista de Antropología Social, 18:21-42.

ZONABEND, Françoise. 1986. "De la familia. Una visión etnológica del parentesco y la familia". In: André Burguière, Christiane Klapisch-Zuber, Martine Segalen y Françoise Zonabend (coords.), Historia de la familia. Tomo I. Madrid: Alianza Editorial. pp. 17-79. 


\section{Resumo}

A "família policial" é uma categoria de forte enraizamento na instituição policial. Alude, em primeira instância, às redes de parentesco de cada policial, mas também opera em outro sentido, mais metafórico, vinculando seus membros à instituição como um todo. Este trabalho procura se ancorar nestes usos e sentidos da "família policial", que remetem a um modelo discursivo apto a configurar uma determinada história institucional. Por que a agência policial escolhe, em determinadas situações, narrar-se como "família"? Que lógicas, sentidos e identidades podem ser construídos através das relações de parentesco? Dar conta destas questões é uma forma de avançar no reconhecimento da importância que reveste o relato a partir do qual se constrói uma determinada instituição.

Palavras-chave "Família policial", Relato, Discurso, Instituição.

\section{Abstract}

"Police family" is a category strongly rooted in the police institution. It alludes, first of all, to the kinship networks of each police officer, but it also operates in a different, more metaphorical, sense, tying its members to the institution as a whole. This article is based on these usages and meanings of the "police family", which refer to a discursive model liable to configure a determinate institutional history. Why does the police force choose, in some situations, to speak of itself as a "family"? What logic, sense or identities can be constructed through kinship relations? Accounting for these questions is a way to further our recognition of the importance of the narrative through which a specific institution is constructed.

Key words "Police family", Narrative, Discourse, Institution. 